\title{
Effect of sample time on urinary lithogenic risk indexes in healthy and stone-forming adults and children
}

\author{
Adrian Rodriguez ${ }^{1}$, Concepcion Saez-Torres ${ }^{1 *}$, Concepcion Mir ${ }^{1,2}$, Paula Casasayas $^{3}$, Nuria Rodriguez ${ }^{3}$, \\ Dolores Rodrigo ${ }^{1,2}$, Guiem Frontera ${ }^{4}$, Juan Manuel Buades ${ }^{5}$, Cristina Gomez ${ }^{6}$, Antonia Costa-Bauza ${ }^{1}$ and Felix Grases ${ }^{1}$
}

\begin{abstract}
Background: The diagnosis and follow-up of stone forming patients is usually performed by analysis of 24-h urine samples. However, crystallization risk varies throughout the day, being higher at night. The main objective of this study is to evaluate the urinary crystallization risk in adults and children by calculating risk indexes based on different collection periods.

Methods: The study included 149 adults (82 healthy and 67 stone-formers) and 108 children (87 healthy and 21 stoneformers). 24-h urine was collected, divided into 12-h daytime sample ( $8 \mathrm{am}$ to $8 \mathrm{pm}$ ), and 12-h overnight sample (8 pm to 8 am next morning). Solute concentrations, the calcium to citrate ratio ( $\mathrm{Ca} / \mathrm{Cit})$, and the ion activity product of calcium oxalate $(\mathrm{AP}[\mathrm{CaOx}])$ and calcium phosphate (AP[CaP]) were calculated in each 12-h sample and in overall 24-h urine. Assessments were also related to stone type.

Results: $\mathrm{Ca} / \mathrm{Cit}$ and $\mathrm{AP}(\mathrm{CaOx})$ were significantly higher in stone forming patients than in healthy subjects. The 12-h overnight samples had the highest values for both risk indexes, confirming a greater risk for crystallization at night. The $\mathrm{AP}(\mathrm{CaP})$ index was significantly higher in patients with pure hydroxyapatite stones than healthy controls, but was not significantly different between stone-formers overall and healthy controls.
\end{abstract}

Conclusions: The calculation of risk indexes is a simple method that clinicians can use to estimate crystallization risk. For this purpose, the use of 12-h overnight urine may be a reliable alternative to 24-h collections.

Keywords: 12-h night urine, AP(CaOx) index, AP(CaP) index, Ca/Cit ratio, Crystallization risk, Renal Lithiasis

\section{Background}

Renal lithiasis has a high prevalence in adults and is relatively rare in children, although it is increasing in all age groups $[1,2]$. Up to $80 \%$ of renal stones contain different forms of calcium oxalate or calcium phosphate crystals [3, 4]. The different types of renal stones have different etiologies, which include particular features of urine composition. Thus, renal calculi consisting of calcium oxalate dihydrate (COD), pure hydroxyapatite (HAP), or admixtured COD $+\mathrm{HAP}$, are more likely to form in the presence of urine with a high level of calcium and a low level of citrate [5]. On the other hand, even at relatively low levels of urinary

\footnotetext{
* Correspondence: currisaez@telefonica.net

${ }^{1}$ Laboratory of Renal Lithiasis Research, University Institute of Health Sciences Research (IUNICS-IdISBa), University of Balearic Islands, Ctra Valldemossa, km 7.5, 07122 Palma de Mallorca, Spain

Full list of author information is available at the end of the article
}

supersaturation, injured papillary tissue can initiate the formation of papillary calcium oxalate monohydrate calculi (COMp) [6], and the presence of heterogeneous nucleating elements is related to the formation of unattached calcium oxalate monohydrate calculi (COMu) [5].

The traditional diagnosis and follow-up of stone-forming patients consists of assessment of the concentration and excretion of different solutes in 24-h urine samples (typically creatinine, calcium, magnesium, phosphate, oxalate, citrate, and uric acid), and measurements of urinary $\mathrm{pH}$ and volume. This approach allows diagnosis of metabolic abnormalities, such as hypercalciuria, hyperoxaluria, and hypocitraturia. However, some patients are classified as having idiopathic renal stones if there is no evidence of a metabolic abnormality. This may be because the key factor for urinary crystallization is not the absolute solute excretions but the urinary supersaturation degree, a parameter that depends on 
urine concentration. For this reason, and due to the multifactorial characteristics of renal lithiasis, some authors have developed different risk indexes to estimate the risk of urinary crystallization $[7,8]$. Several studies used these indexes, including the calcium/citrate ratio, the ion activity product of calcium oxalate (AP $[\mathrm{CaOx}])$, and calcium phosphate $(\mathrm{AP}[\mathrm{CaP}])$, to compare stone-forming children and adults with healthy controls, and found significant differences [7, 9-11]. Furthermore, previous studies have shown cut off values for urinary solute concentrations that makes urine prone to crystallize in an in vitro model $[12,13]$.

On the other hand, when performing the metabolic evaluation of the stone forming patient, it must be considered that urinary composition varies throughout the day, leading to a higher risk of crystallization at night. More precisely, there is a 12-h high-risk period from 8 p.m. to 8 a.m. [14]. However, to our knowledge, no study has yet compared the stone risk factors in 12-h overnight samples with 12-h daytime urine samples.

Thus, the objectives of this study are to (i) evaluate the urinary crystallization risk by measuring urinary solute concentrations and calculating risk formulas in children and adults with and without a history of lithiasis, (ii) compare the results of the risk parameters in 12-h daytime, 12-h overnight, and overall 24-h urine, and (iii) examine the relationships of the different risk formulas with stone type.

\section{Methods}

\section{Study subjects}

This study examined 257 participants who were divided into four groups: 87 healthy children (4-17 years), 21 stone-forming children (4-17 years), 82 healthy adults (2357 years), and 67 stone-forming adults (18-71 years). Healthy children were recruited from schools, both primary and secondary. Stone formers were from the pediatric nephrology unit or the urology department of our tertiary hospital. All stone-formers had a confirmed history of renal lithiasis in the previous 2 years. Subjects with a history of disorders that could affect urine chemistry (bowel disease with malabsorption, bone fracture, active urinary tract infection, chronic kidney disease, metabolic syndrome) were excluded. Medications, including diuretics and alkali citrate, were discontinued three days before urine collection. Participants were told not to change their normal diet and physical activity. We obtained approval from the local Ethics Committee (IB3152/16) and informed consent from each participant or his/her legal representative.

\section{Renal calculi analysis}

Stone analysis was performed by stereoscopic microscopy (Optomic, Madrid, Spain), scanning electron microscopy (S-530 M, Hitachi, Tokyo, Japan), X-ray microanalysis (Oxford Link Isis; Oxford, UK), and infrared spectrometry (Infrared Spectroscope Bruker IFS66; Bruker, Ettlingen, Germany).
The obtained stones were classified into 5 groups [5]: calcium oxalate monohydrate renal calculi developed on papillary tissue (COMp); unattached calcium oxalate monohydrate calculi (COMu); calcium oxalate dihydrate calculi (COD); calcium oxalate dihydrate-hydroxyapatite mixed calculi (COD+HAP); and hydroxyapatite (HAP) calculi. In recurrent stone-formers with different types of calculi, the last calculus was used for classification.

\section{Urine collection and analysis}

Twenty-four-hour urine was collected in two separate flasks with thymol. The 12-h daytime sample began at 8 a.m. (after discarding first morning urine) and ended at 8 p.m.; at this time, participants were instructed to perform a micturition in the daytime bottle. The 12-h nighttime sample began at 8 p.m. and was collected until 8 a.m. on the next day (fasting state). Sampling adequacy was determined by asking participants about the completeness of urine collection and by using the recently-reported anthropometry-based age and sex-specific reference values for 24-h urinary creatinine excretion $[15,16]$.

Urinary volume, $\mathrm{pH}$ (measured using a Crison $\mathrm{pH}$-meter), and the concentrations of creatinine, calcium, phosphorus, oxalate, uric acid, citrate, and magnesium were determined. Phosphorus was measured by the ammonium molybdate reduction method, magnesium by an enzymatic assay, calcium by a colorimetric reaction with Arsenazo III calcium-sensitive dye, uric acid by the uricase method, and creatinine using the Jaffe method. These analyses were performed using an Architect C16000 Autoanalyzer (Abbott Diagnostics, Illinois, USA). Urinary citrate was measured by an enzymatic assay (Biosystems, Barcelona, Spain), and urinary oxalate was determined using the oxalate oxidase/peroxidase method (LTA, Milano, Italy). All parameters were measured separately in 12-h samples, and then calculated for the overall 24-h urine.

The crystallization risk of urine was determined by the calcium-to-citrate ratio $(\mathrm{Ca} / \mathrm{Cit})$ and two modified estimates of $\mathrm{AP}(\mathrm{CaOx})$ and the $\mathrm{AP}(\mathrm{CaP})$, as described by Tiselius $[17,18]$ :

$$
\begin{aligned}
\mathrm{AP}(\mathrm{CaOx}) \text { index }=\mathrm{A} & \times \mathrm{Ca}^{0.84} \times \mathrm{Ox}^{\circ} \mathrm{Mg}^{-0.12} \\
& \times \mathrm{Cit}^{-0.22} \times \mathrm{V}^{-1.03}
\end{aligned}
$$

in which A is 2.7 for a 12 -h sample, and 1.9 for a $24-\mathrm{h}$ sample.

$$
\begin{aligned}
\mathrm{AP}(\mathrm{CaP}) \text { index }=0.0032 & \times \mathrm{Ca}^{1.07} \times \mathrm{P}^{0.70} \times(\mathrm{pH}-4.5)^{6.8} \\
& \times \mathrm{Mg}^{-0.12} \times \mathrm{Cit}^{-0.20} \times \mathrm{V}^{-1.31}
\end{aligned}
$$

which was only calculated for 12 -h samples, because $\mathrm{pH}$ was not determined for 24-h samples. 


\section{Statistical analysis}

Descriptive data are presented as medians and interquartile ranges. The Wilcoxon sum-rank test was used to compare groups. The Wilcoxon signed-rank test was used to compare daytime and nighttime samples. After examined the Bonferroni, Holm and Hochberg corrections, we considered a $p$-value of 0.001 or less as statistically significant. IBM SPSS Statistics version $22^{\circ}$ for Windows was used for statistical analyses.

\section{Results}

There were 257 study participants. The healthy and stone-forming adults had similar anthropometric characteristics, as did the healthy and stone-forming children (Table 1). Among adult stone formers, 11 had COMp stones, 11 had COMu stones, 18 had COD stones, 10 had HAP + COD stones, 4 had HAP stones, and stone analysis was unavailable for 13 patients. Among stone-forming children, 9 had COD stones, 1 had HAP + COD stones, and stone analysis was unavailable for the other 11 children.

Table 2 summarizes the urinary volume and solute concentrations in 24-h urine samples. Oxalate concentration was significantly higher in stone-forming than healthy adults; calcium concentration was significantly higher in stone-forming than healthy children.

The $\mathrm{AP}(\mathrm{CaOx})$ index and $\mathrm{Ca} / \mathrm{Cit}$ ratio in 24-h urine samples were significantly higher in stone-formers than in healthy subjects, among children and adults $(p<0.001$ for both comparisons) (Fig. 1).

Measurements of risk indexes in 12-h samples are shown in Table 3 (adults) and Table 4 (children). Regarding $\mathrm{AP}(\mathrm{CaOx})$ index and $\mathrm{Ca} / \mathrm{Cit}$, significant differences between patients and healthy subjects were observed when we performed the comparisons using only the 12-h day sample or the 12-h night urine fractions $(p<0.001)$. On the contrary, for the $\mathrm{AP}(\mathrm{CaP})$ index in 12-h samples, the differences did not reach statistical significance, neither in the daytime nor in the overnight sample analysis.

Tables 3 and 4 also compare the urinary parameters of daytime and overnight samples. Healthy and stone-forming adults had significant differences in

Table 1 Anthropometric measures of the four study groups

\begin{tabular}{lllll}
\hline & $\begin{array}{l}\text { Healthy } \\
\text { adults }(N=82)\end{array}$ & $\begin{array}{l}\text { Stone forming } \\
\text { adults }(N=67)\end{array}$ & $\begin{array}{l}\text { Healthy } \\
\text { children } \\
(N=87)\end{array}$ & $\begin{array}{l}\text { Stone forming } \\
\text { children } \\
(N=21)\end{array}$ \\
\hline \% men & 46 & 55 & 57 & 64 \\
Age (years) & $40(10)$ & $46(13)$ & $12(3)$ & $12(4)$ \\
Weight $(\mathrm{kg})$ & $68(13)$ & $71(16)$ & $46(14)$ & $44(18)$ \\
Height $(\mathrm{cm})$ & $170(8)$ & $167(10)$ & $151(17)$ & $147(21)$ \\
BMl $\left(\mathrm{kg} / \mathrm{m}^{2}\right)$ & $24(3)$ & $25(4)$ & $19(3)$ & $19(9)$ \\
\hline
\end{tabular}

Results are expressed as \% or mean (SD) magnesium, phosphate, urinary $\mathrm{pH}, \mathrm{Ca} / \mathrm{Cit}$, and $\mathrm{AP}(\mathrm{CaP})$. On the contrary, healthy subjects had a lower nighttime urinary volume, and stone-formers had a greater nighttime $\mathrm{AP}(\mathrm{CaOx})$. Comparison of daytime and nighttime samples in children indicated the healthy children had significant differences in all parameters except uric acid concentration. On the contrary, in the stone forming children group, some differences did not reach significance due to the small size of the sample.

Figure 2 shows the $\mathrm{AP}(\mathrm{CaOx})$ index, $\mathrm{AP}(\mathrm{CaP})$ index, and the $\mathrm{Ca} / \mathrm{Cit}$ ratio for the 12 -h overnight urine samples of stone-forming adults according to calculus composition. Patients whose calculi were COD or COD + HAP had higher $\mathrm{AP}(\mathrm{CaOx})$ indexes, while patients with pure HAP calculi had higher $\mathrm{AP}(\mathrm{CaP})$ indexes. Patients with COD, HAP, and COD+HAP calculi had higher $\mathrm{Ca} /$ Cit ratios. The evaluation of risk indexes in relation to stone composition performed in 12-h daytime urine and in 24-h urine showed a similar pattern of differences than observed in the 12-h overnight urine, although for $\mathrm{AP}(\mathrm{CaP})$ there were more overlapping results in the daytime than in overnight samples (data not shown).

\section{Discussion}

The main findings of this study are that the $\mathrm{AP}(\mathrm{CaOx})$ and $\mathrm{Ca} / \mathrm{Cit}$ values were significantly higher in the urine of stone-forming children and adults than in the corresponding healthy controls, being the results also evident by the only analysis of the 12-h overnight urine fraction. These indexes vary according to stone composition in adults. In addition, the $\mathrm{AP}(\mathrm{CaP})$ index was only elevated in adults with phosphate stones.

Previous studies have repeatedly stressed the important role of urine supersaturation in the genesis of renal calculi [8]. However, neither the European Association of Urology nor the American Urological Association includes calculation of supersaturation in their guidelines for evaluation of patient with renal lithiasis $[19,20]$. In fact, some authors do not perform these measurements because they believe there is only limited evidence that monitoring of supersaturation in urine can prevent stone recurrence [21]. On the contrary, other authors have stated that assessment of urinary lithogenic risk, determined by measuring data related to the extent of supersaturation, is useful for guiding treatment and checking patient compliance [22, 23]. The use of specific easy-calculating formulas for estimation of supersaturation overcomes several methodological pitfalls of other procedures $[7,8,10]$. We found that $\mathrm{AP}(\mathrm{CaOx})$ and $\mathrm{Ca} /$ Cit values provided reliable estimates of the risk of renal lithiasis, in that each was significantly higher in stone-forming children and adults than the corresponding healthy controls. In the case of the $\mathrm{AP}(\mathrm{CaP})$ index, we observed differences in patients with phosphate 
Table 2 Urinary volume and solute concentrations in 24-h urine samples of the four study groups

\begin{tabular}{|c|c|c|c|c|c|c|}
\hline & \multicolumn{3}{|l|}{ Adults } & \multicolumn{3}{|l|}{ Children } \\
\hline & Healthy & Stone formers & $p$-value & Heatlhy & Stone formers & $p$-value \\
\hline Volume (mL/24 h) & 1573 (1189-2173) & $1778(1250-2380)$ & 0.089 & $876(672-1180)$ & $1100(645-1707)$ & 0.111 \\
\hline Creatinine (mg/L) & $919(648-1230)$ & 804 (571-1098) & 0.106 & 970 (763-1294) & $796(565-1245)$ & 0.007 \\
\hline Calcium (mg/L) & $106(70-179)$ & 124 (89-174) & 0.166 & $72(45-120)$ & $130(72-231)$ & $<0.001$ \\
\hline Magnesium (mg/L) & $64(44-86)$ & $55(43-76)$ & 0.143 & $113(77-142)$ & $93(52-125)$ & 0.081 \\
\hline Oxalate (mg/L) & $15(12-19)$ & $20(14-24)$ & 0.001 & $22(17-29)$ & $25(22-32)$ & 0.120 \\
\hline Phosphorous (mg/L) & 517 (397-784) & $515(357-637)$ & 0.207 & 840 (597-1063) & 597 (430-768) & 0.002 \\
\hline Uric acid (mg/L) & $369(272-513)$ & $343(258-481)$ & 0.334 & $548(393-691)$ & $411(298-606)$ & 0.018 \\
\hline Citrate (mg/L) & 435 (286-676) & $322(226-470)$ & 0.003 & 517 (373-722) & 347 (205-626) & 0.005 \\
\hline
\end{tabular}

Results are expressed as median $\left(\mathrm{P}_{25}-\mathrm{P}_{75}\right)$. Statistical comparisons are between healthy and stone-forming adults, and between healthy and stone-forming children

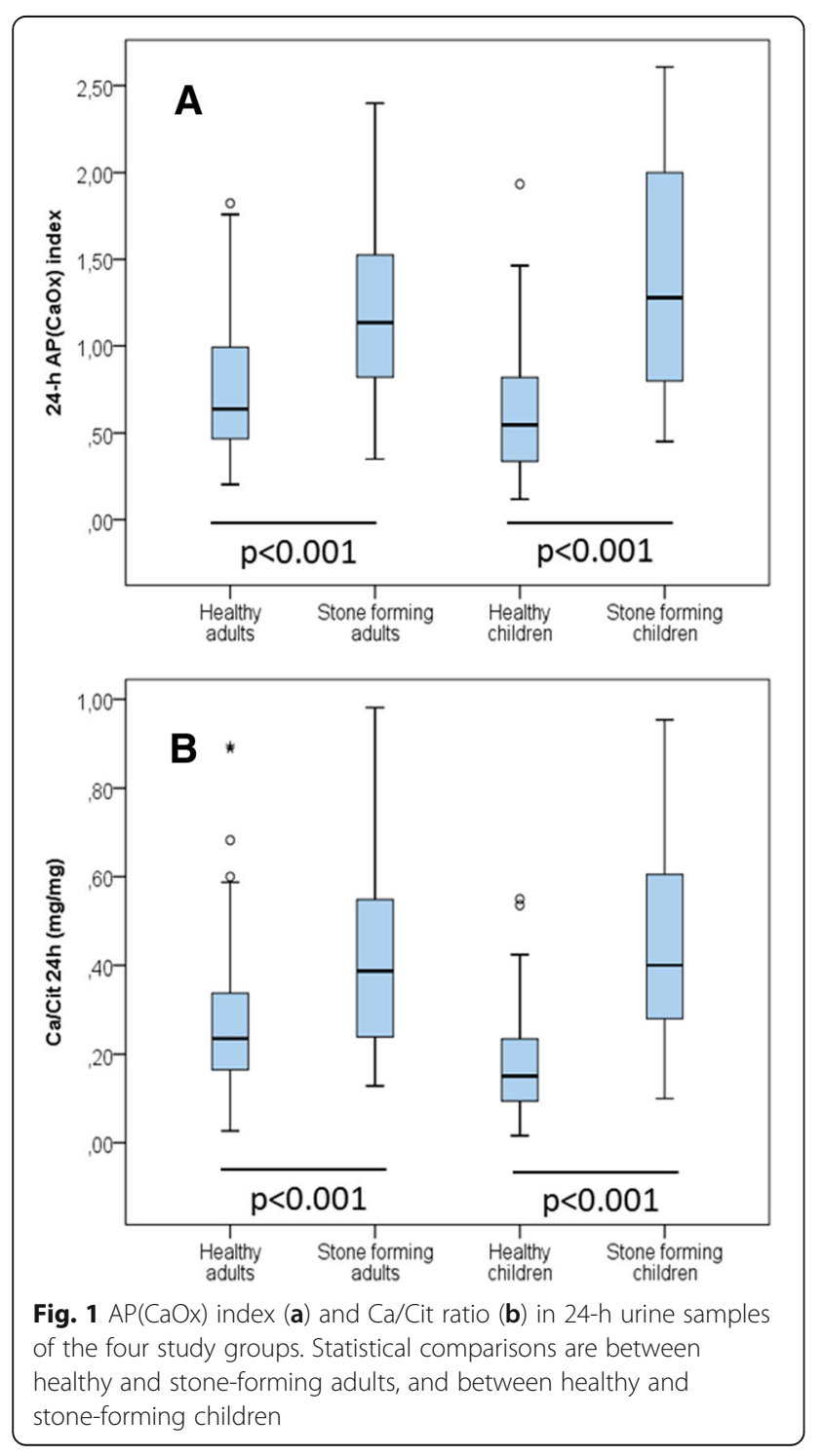

stones, but not stone-formers overall, because most subjects had calcium oxalate stones.

Use of the $\mathrm{Ca} / \mathrm{Cit}$ ratio to assess the risk of renal lithiasis is widespread in the literature and in clinical practice [9]. Calculation of AP indexes allows integration of information on additional components of urine, as well as urine volume. Regarding cut-off points for the different indexes, the overlap of index values in the healthy and stone-forming groups means it is difficult to establish precise values to discriminate subjects with and without risk. Despite this, we believe these indexes provide relevant information, because higher index values indicate higher risk of crystallization in urine [24].

Some researchers have recommended that supersaturation be assessed in 24-h urine samples before treatment, 4-6 weeks afterwards, and in subsequent follow-ups [25]. However, collection of urine over $24 \mathrm{~h}$ can be cumbersome, so a simpler sampling method would be more convenient for patients. Our results show that the $\mathrm{AP}(\mathrm{CaOx})$ and $\mathrm{Ca} / \mathrm{Cit}$ in 12 -h overnight urine samples were significantly different in stone-forming and healthy individuals. Moreover, the overnight samples had higher values for both risk indexes than the 12-h daytime samples and the 24-h samples. These findings support previous evidence that averaging results from the whole day masks peaks of lithogenic risk that occur at nighttime $[14,26]$. Therefore, the analysis of a 12 -h overnight sample is more convenient for patients and appears to be more sensitive in detection of increased risk of crystallization of urine. Considering that the night is a period of high urinary crystallization risk, the advice of increasing fluid intake at the late evening should be strongly encouraged in order to decrease urinary supersaturation degree.

Our data on the $\mathrm{AP}(\mathrm{CaP})$ index indicated the highest values were in daytime urine. This is due to diurnal variations in $\mathrm{pH}$, which strongly affects calcium phosphate solubility $[27,28]$. Urinary $\mathrm{pH}$ increases during the day, and so does calcium phosphate supersaturation [29]. 
Table 3 Urinary volume, pH, solute concentrations, Ca/Cit ratio, and AP indexes in 12-h daytime and 12-h overnight urine samples of healthy and stone-forming adults

\begin{tabular}{|c|c|c|c|c|c|c|}
\hline & Healthy adults ( $n=$ & & & Stone forming ad & $=67)$ & \\
\hline & 12-h day & 12-h night & $p$-value & 12-h day & 12-h night & $p$-value \\
\hline Volume (mL/12 h) & $870(600-1165)$ & $650(481-1010)$ & 0.001 & $920(700-1200)$ & $780(600-1135)$ & 0.071 \\
\hline Creatinine (mg/dL) & $940(560-1310)$ & 1025 (670-1563) & 0.002 & 736 (562-1233) & $946(553-1224)$ & 0.192 \\
\hline Calcium (mg/L) & $90(72-161)$ & $133(63-201)$ & 0.060 & $123(84-167)$ & $142(90-184)$ & 0.031 \\
\hline Magnesium (mg/L) & $52(37-81)$ & $79(50-109)$ & $<0.001$ & $49(38-68)$ & $68(50-90)$ & $<0.001$ \\
\hline Oxalate (mg/L) & $15(11-19)$ & $16(11-23)$ & 0.04 & $18(14-24)$ & $21(15-27)$ & 0.003 \\
\hline Phosphorous (mg/L) & $469(353-683)$ & 651 (442-1085) & $<0.001$ & $473(314-622)$ & $581(382-773)$ & $<0.001$ \\
\hline Uric acid (mg/L) & $426(278-556)$ & $372(226-526)$ & 0.259 & $395(263-499)$ & $338(241-473)$ & 0.031 \\
\hline Citrate (mg/L) & $495(315-754)$ & $408(232-710)$ & 0.016 & $347(223-531)$ & $324(205-434)$ & 0.047 \\
\hline $\mathrm{pH}$ & $6.27(5.95-6.71)$ & $5.64(5.43-5.98)$ & $<0.001$ & $6.12(5.71-6.60)$ & $5.79(5.49-6.16)$ & $<0.001$ \\
\hline $\mathrm{Ca} / \mathrm{Cit}$ (mg/mg) & $0.21(0.15-0.30)$ & $0.25(0.18-0.42)$ & $<0.001$ & $0.34(0.21-0.44)$ & $0.43(0.26-0.64)$ & $<0.001$ \\
\hline AP $(\mathrm{CaOx})$ index & $0.64(0.49-0.90)$ & $0.66(0.46-1.13)$ & 0.057 & $1.10(0.66-1.54)$ & $1.35(0.90-1.84)$ & 0.001 \\
\hline AP $(\mathrm{CaP})$ index & 4.85 (1.09-18.24) & $0.33(0.06-2.49)$ & $<0.001$ & $3.41(0.36-15.30)$ & $0.93(0.07-7.87)$ & 0.001 \\
\hline
\end{tabular}

Results are expressed as median $\left(\mathrm{P}_{25}-\mathrm{P}_{75}\right)$

However, we think that use of overnight urine is preferable to daytime or 24-h urine for evaluation of the risk of calcium phosphate stones. Remarkably, we found that the $\mathrm{AP}(\mathrm{CaP})$ index had a much wider range in daytime than in overnight urine, and also had more overlap in relation to stone type. The influence of punctual food intake on urinary $\mathrm{pH}$ can explain this daytime variability. At night, fasting makes $\mathrm{pH}$ values decrease and stabilize [30], so the differences between patients with pure calcium phosphate stones and other types of stones were more evident.

In agreement with other studies, we observed a correlation between the indexes and renal stone type in adults. Thus, we believe that these risk indexes might be helpful in cases when analysis of calculus composition is unavailable, because the results may suggest the chemical composition of the stone.

A limitation of this study is that we only enrolled a small number of stone-forming children because renal lithiasis is very rare at this age. However, our observation of similar patterns in children and adults suggest that the findings of the larger adult group may also be applicable to children. Another limitation is that we did not have the stone composition for all patients, and that very few patients had HAP stones. However, our results provide a foundation for further studies of renal lithiasis in children and of the relationship of different indexes with stone composition. Furthermore, more data is warranted, including a higher

Table 4 Urinary volume, pH, solute concentrations, Ca/Cit ratio, and AP indexes in 12-h daytime and 12-h overnight urine samples of healthy and stone-forming children

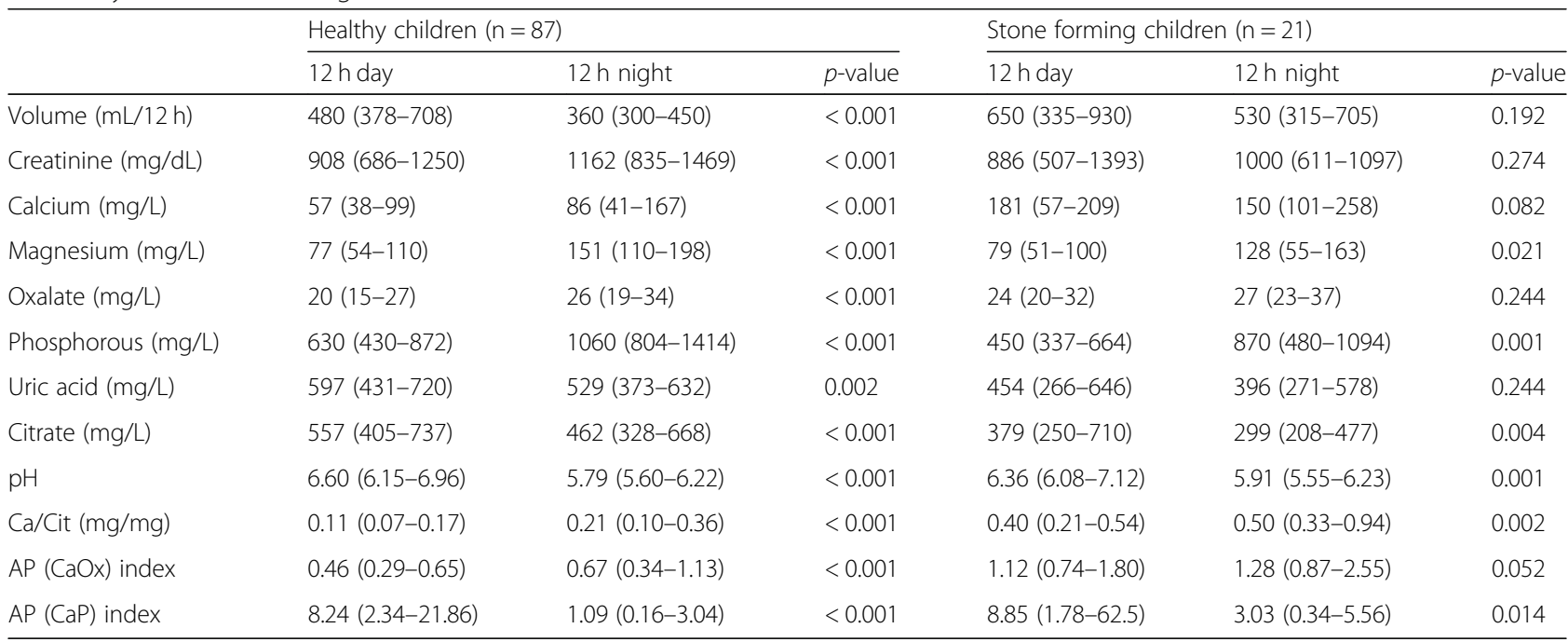

Results are expressed as median $\left(\mathrm{P}_{25}-\mathrm{P}_{75}\right)$ 

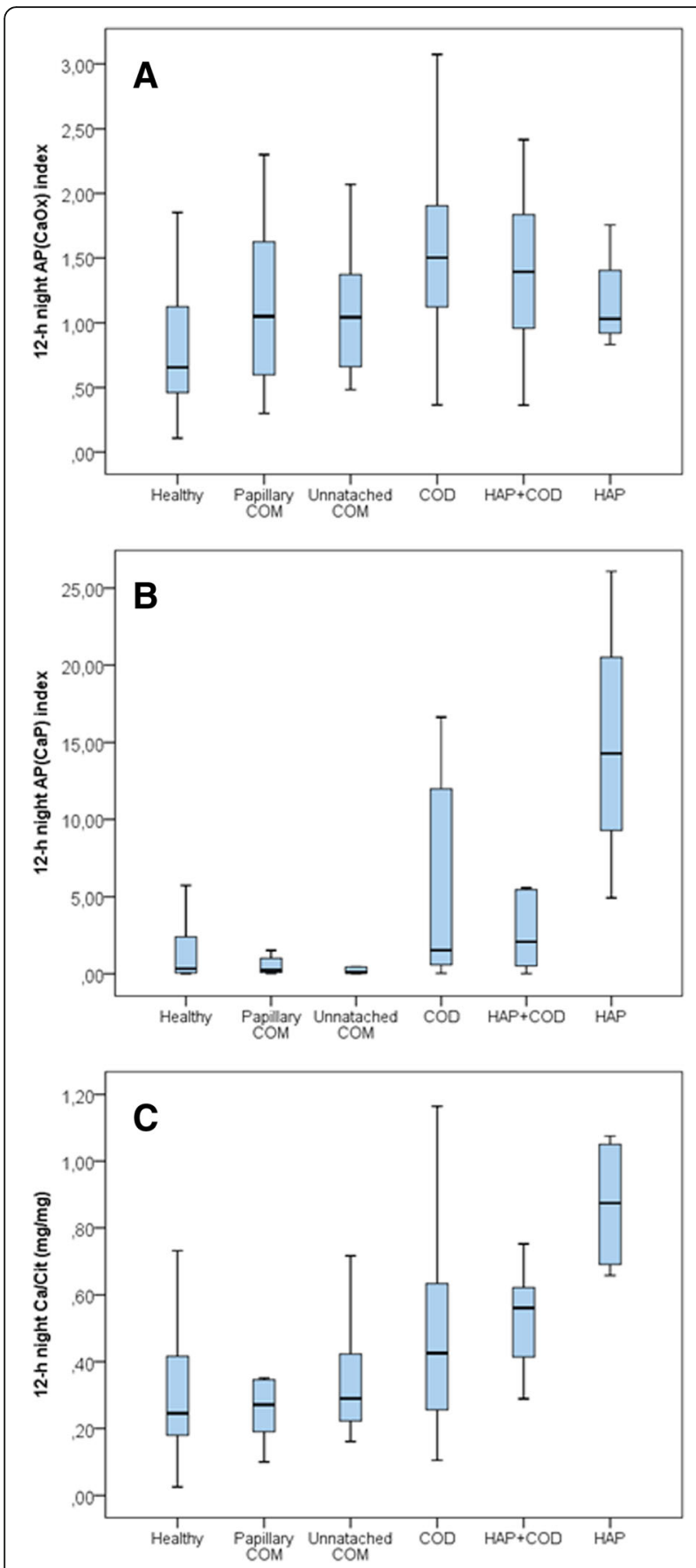

Fig. $2 \mathrm{AP}(\mathrm{CaO})$ index (a), $\mathrm{AP}(\mathrm{CaP})$ index (b), and $\mathrm{Ca} / \mathrm{Cit}$ ratio (c) in 12-h overnight urine samples of adult stone-formers according to calculus composition

number of patients, in order to help determine a cutoff value for the studied indexes.

\section{Conclusions}

Calculation of renal lithiasis risk indexes is easy and may facilitate the decision-making process for treatment of stone-forming patients because the indexes, which integrate the results of multiple urinary parameters, have shown higher values in stone forming patients that in healthy subjects. These differences have been more evident in the $12 \mathrm{~h}$ overnight urine sample. Our results indicate that use of a 12-h overnight urine sample should be considered as a complementary information to that provided by the analysis of 24-h samples when evaluating lithogenic risk, because collection of the overnight sample is more convenient and has higher values in all tested indexes.

\section{Abbreviations}

$\mathrm{AP}(\mathrm{CaO} x)$ : ion activity product of calcium oxalate; $\mathrm{AP}(\mathrm{CaP})$ : ion activity product of calcium phosphate; Ca: calcium; Cit: citrate; COD: calcium oxalate dihydrate; COMp: papillary calcium oxalate monohydrate; COMu: unattached calcium oxalate monohydrate; HAP: hydroxyapatite

\section{Acknowledgements}

A.R. is grateful to the European Social Fund and the Conselleria d'Educació, Cultura i Universitats for the fellowship FPI/1570/2013.

\section{Funding}

This work was supported by project grant AAEE42/2015 from Conselleria d'Innovació, Recerca i Turisme, Govern de les Illes Balears. The funders play no role in the design of the study and collection, analysis, and interpretation of data and in writing the manuscript.

\section{Availability of data and materials}

The datasets used and/or analysed during the current study are available from the corresponding author on reasonable request.

\section{Authors' contribution}

AR: healthy subjects recruitment; data analysis; laboratory analysis and manuscript drafting. CST: healthy subjects recruitment; design protocol; manuscript drafting and revision. CM: healthy and stone-forming children recruitment and manuscript drafting. PC: Stone-forming adults recruitment and manuscript drafting. NR: Stone-forming adults recruitment and manuscript drafting. DR: healthy and stone-forming children recruitment and manuscript revision. GF: data analysis and manuscript revision. JMB: Stone-forming adults recruitment and manuscript revision. CG: Laboratory analysis and manuscript revision. ACB: conception and design and manuscript revision. FG: conception and design and manuscript revision. All authors have read and approved the final version of the manuscript.

\section{Ethics approval and consent to participate}

We obtained approval from the Ethics Committee of the Balearic Islands (IB3152/16) and written informed consent from each participant or his/her legal representative.

\section{Consent for publication}

Not applicable.

\section{Competing interest}

The authors declare that the have no competing interests.

\section{Publisher's Note}

Springer Nature remains neutral with regard to jurisdictional claims in published maps and institutional affiliations.

\section{Author details}

${ }^{1}$ Laboratory of Renal Lithiasis Research, University Institute of Health Sciences Research (IUNICS-IdISBa), University of Balearic Islands, Ctra Valldemossa, km 7.5, 07122 Palma de Mallorca, Spain. ${ }^{2}$ Department of Pediatric Nephrology, Son Espases Universitary Hospital, 07020 Palma de Mallorca, Spain.

${ }^{3}$ Department of Urology, Son Llatzer Hospital, 07198 Palma de Mallorca, Spain. ${ }^{4}$ Research Unit, Son Espases Universitary Hospital, 07020 Palma de Mallorca, Spain. ${ }^{5}$ Department of Nephrology, Son Llatzer Hospital, 07198 Palma de Mallorca, Spain. ${ }^{6}$ Clinical Analysis Service, Son Espases Universitary Hospital, 07020 Palma de Mallorca, Spain. 
Received: 26 June 2018 Accepted: 10 December 2018

Published online: 19 December 2018

\section{References}

1. Scales CD Jr, Smith AC, Hanley JM, Saigal CS. Prevalence of kidney stones in the United States. Eur Urol. 2012;62:160-5.

2. VanDervoort K, Wiesen J, Frank R, Vento S, Crosby V, Chandra M, et al. Urolithiasis in pediatric patients: a single center study of incidence, clinical presentation and outcome. J Urol. 2007;177:2300-5.

3. Cloutier J, Villa L, Traxer O, Daudon M. Kidney stone analysis: "give me your stone, I will tell you who you are!". World J Urol. 2015;33:157-69.

4. Costa-Bauza A, Ramis M, Montesinos V, Grases F, Conte A, Piza P, et al. Type of renal calculi: variation with age and sex. World J Urol. 2007:25:415-21.

5. Grases F, Costa-Bauza A, Ramis M, Montesinos V, Conte A. Simple classification of renal calculi closely related to their micromorphology and etiology. Clin Chim Acta. 2002;322:29-36.

6. Grases F, Costa-Bauza A, Bonarriba CR, Pieras EC, Fernandez RA, Rodriguez A. On the origin of calcium oxalate monohydrate papillary renal stones. Urolithiasis. 2015;43(Suppl 1):33-9.

7. Sikora P, Zajaczkowska M, Hoppe B. Assessment of crystallization risk formulas in pediatric calcium stone-formers. Pediatr Nephrol. 2009;24:1997-2003.

8. Baumann JM, Affolter B. From crystalluria to kidney stones, some physicochemical aspects of calcium nephrolithiasis. World J Nephrol. 2014;3:256-67.

9. Arrabal-Polo MA, Arrabal-Martin M, Arias-Santiago S, Garrido-Gomez J, Poyatos-Andujar A, Zuluaga-Gomez A. Importance of citrate and the calcium : citrate ratio in patients with calcium renal lithiasis and severe lithogenesis. BJU Int. 2013;111:622-7.

10. Tiselius HG. Risk formulas in calcium oxalate urolithiasis. World J Urol. 1997; 15:176-85.

11. Tiselius HG. Estimated levels of supersaturation with calcium phosphate and calcium oxalate in the distal tubule. Urol Res. 1997;25:153-9.

12. Grases F, Costa-Bauza A, Prieto RM, Arrabal M, De Haro T, Lancina JA, et al. Urinary lithogenesis risk tessts: comparison of a commercial kit and a laboratory prototype test. Scand J Urol Nephrol. 2011;45:312-8.

13. Saez-Torres C, Grases F, Rodrigo D, Garcia-Raja AM, Gomez C, Frontera G. Risk factors for urinary stones in healthy schoolchildren with and without a family hystory of nephrolithiasis. Pedriatr Nephrol. 2013;28:639-45.

14. Tiselius HG. Should we modify the principles of risk evaluation and recurrence preventive treatment of patients with calcium oxalate stone disease in view of the etiologic importance of calcium phosphate? Urolithiasis. 2015:43(Suppl 1):47-57.

15. Forni Ogna V, Ogna A, Vuistiner P, Pruijm M, Ponte B, Ackermann D, et al. New anthropometry-based age- and sex-specific reference values for urinary 24-hour creatinine excretion based on the adult Swiss population. BMC Med. 2015;13:40.

16. Remer T, Neubert A, Maser-Gluth C. Anthropometry-based reference values for 24-h urinary creatinine excretion during growth and their use in endocrine and nutritional research. Am J Clin Nutr. 2002;75:561-9.

17. Tiselius HG. Aspects on estimation of the risk of calcium oxalate crystallization in urine. Urol Int. 1991:47:255-9.

18. Bek-Jensen $\mathrm{H}$, Tiselius HG. Evaluation of urine composition and calcium salt crystallization properties in standardized volume-adjusted 12-h night urine from normal subjects and calcium oxalate stone formers. Urol Res. 1997;25:365-72.

19. Skolarikos A, Straub M, Knoll T, Sarica K, Seitz C, Petrik A, et al. Metabolic evaluation and recurrence prevention for urinary stone patients: EAU guidelines. Eur Urol. 2015;67:750-63.

20. Pearle MS, Goldfarb DS, Assimos DG, Curhan G, Denu-Ciocca CJ, Matlaga BR, et al. Medical management of kidney stones: AUA guideline. J Urol. 2014; 192:316-24.

21. Hsi RS, Sanford T, Goldfarb DS, Stoller ML. The role of the 24-hour urine collection in the prevention of kidney stone recurrence. J Urol. 2017;197: 1084-9.

22. Gambaro G, Croppi E, Coe F, Lingeman J, Moe O, Worcester E, et al. Metabolic diagnosis and medical prevention of calcium nephrolithiasis and its systemic manifestations: a consensus statement. J Nephrol. 2016;29:715-34.

23. Parks JH, Coward M, Coe FL. Correspondence between stone composition and urine supersaturation in nephrolithiasis. Kidney Int. 1997:51:894-900.

24. Curhan GC, Willett WC, Speizer FE, Stampfer MJ. Twenty-four-hour urine chemistries and the risk of kidney stones among women and men. Kidney Int. 2001;59:2290-8.
25. Coe FL, Worcester EM, Evan AP. Idiopathic hypercalciuria and formation of calcium renal stones. Nat Rev Nephrol. 2016;12:519-33.

26. Porowski T, Kirejczyk JK, Zoch-Zwierz W, Konstantynowicz J, KorzenieckaKozerska A, Motkowski R, et al. Assessment of lithogenic risk in children based on a morning spot urine sample. J Urol. 2010;184:2103-8.

27. Wagner CA, Mohebbi N. Urinary pH and stone formation. J Nephrol. 2010; 23(Suppl 16):S165-9.

28. Grases F, Costa-Bauza A, Gomila I, Ramis M, Garcia-Raja A, Prieto RM. Urinary pH and renal lithiasis. Urol Res. 2012;40:41-6.

29. Murayama T, Sakai N, Yamada T, Takano T. Role of the diurnal variation of urinary $\mathrm{pH}$ and urinary calcium in urolithiasis: a study in outpatients. Int J Urol. 2001;8:525-31.

30. Firsov D, Bonny O. Circadian regulation of renal function. Kidney Int. 2010; 78:640-5
Ready to submit your research? Choose BMC and benefit from:

- fast, convenient online submission

- thorough peer review by experienced researchers in your field

- rapid publication on acceptance

- support for research data, including large and complex data types

- gold Open Access which fosters wider collaboration and increased citations

- maximum visibility for your research: over $100 \mathrm{M}$ website views per year

At BMC, research is always in progress.

Learn more biomedcentral.com/submissions 